\title{
El compromiso en la teoría crítica. Un análisis de tres textos de Horkheimer ${ }^{1}$
}

\author{
Eugenia Fraga
}

Resumen: En el presente trabajo analizaremos tres textos clave de la obra de Horkheimer ("Montaigne y la función del escepticismo", "La función social de la filosofía", y Dialéctica de la ilustración), intentando rastrear en ellos el concepto de compromiso entendido como elemento fundamental de la teoría crítica para las ciencias sociales. Al hacerlo, hallaremos ecos de la perspectiva de Marx, e interpretaremos al compromiso como un posicionamiento que se distancia tanto del relativismo como del dogmatismo.

Palabras clave: Max Horkheimer; teoría crítica; compromiso

\section{Commitment in critical theory. An analysis of three key texts from Horkheimer}

\begin{abstract}
In this paper we will analize three key texts from Horkheimer's work ("Montaigne and the function of skepticism", "The social function of philosophy", and The dialectic of enlightenment), trying to seek in them the concept of commitment, understood as fundamental element of a critical theory for the social sciences. In doing this, we will find echoes of Marx's perspective, and we will interpret commitment as a position that takes distance both from relativism and from dogmatism.
\end{abstract}

Keywords: Max Horkheimer; critical theory; commitment

${ }^{1}$ Recebido em 20/02/17 e aprovado em 24/05/18.

${ }^{2}$ Docente en materia Sociología Sistemática de la carrera de Sociología de la Facultad de Ciencias Sociales de la Universidad de Buenos Aires, Argentina. E-mail: euge.fraga@hotmail.com 


\title{
O compromisso na teoria crítica. Um análise de três textos-chave de Horkheimer
}

\begin{abstract}
Resumo: No presente trabalho, analisaremos três textos-chave da obra de Horkheimer ("Montaigne e a função do ceticismo", "A função social da filosofia" e a Dialética da ilustração), tentando traçar-lhes o conceito de compromisso entendido como elemento fundamental da teoria crítica para as ciências sociais. Ao fazê-lo, encontraremos ecos da perspectiva de Marx, e interpretaremos o compromisso como uma posição que se distanciará do relativismo e do dogmatismo.
\end{abstract}

Palavras-chave: Max Horkheimer; teoria crítica; compromisso

\section{Introducción}

La obra de un autor fundamental del pensamiento comprometido como Max Horkheimer, miembro y líder de la llamada Escuela de Frankfurt, es amplia y profusa (WIGGERSHAUS, 2010; FRAGA, 2015). Comienza en los años veinte y se extiende hasta inicios de los años setenta del pasado siglo. Por ello, para poder realizar un estudio minucioso de sus muchos textos, que pueda rescatar de ellos la riqueza y la sutileza del análisis, es necesario dividir el trabajo en partes y analizar cada texto en profundidad. Entonces, del total de la obra del autor, aquí examinaremos tres textos, ubicados entre fines de la década del treinta y fines de la década del cuarenta -es decir, en la etapa "intermedia" de la obra horkheimeriana- pues ellos resultan los escritos "claves" para entender su mirada respecto del problema del "compromiso". En efecto, en el artículo "Montaigne y la función del escepticismo", el artículo "La función social de la filosofía", y el famoso y coautorado libro Dialéctica de la ilustración, el concepto de "compromiso" se vuelve central. A continuación, entonces, nos abocaremos a estudiarlos en detalle, enmarcando la problemática específica en torno al compromiso, en la propuesta singular de Horkheimer de una "teoría crítica". 


\section{Montaigne y la función del escepticismo (1938)}

Comencemos por el primer texto de este período clave del pensamiento horkheimeriano. En "Montaigne y la función del escepticismo", publicado en 1938 en la Revista para la investigación social, órgano impreso de la Escuela de Frankfurt, nuestro autor comienza realzando la importancia del pensamiento escéptico moderno, especialmente en la forma de uno de sus más paradigmáticos representantes, Michel de Montaigne (2005)³. El escepticismo de Montaigne se caracteriza por criticar toda opinión absoluta, sea en el campo del saber o en el de la moral, mostrando que nadie puede "erigirse en juez" de modo de determinar cuál de las causas en disputa tiene la razón de su parte, y mostrando asimismo que a toda causa que en un momento se tiene por "absolutamente cierta" le ha antecedido otra diferente y le seguirá aún otra, de modo tal que la razón parece más bien ser una cuestión de modas. Las convicciones, señala Montaigne, son producto simplemente de la costumbre, la tradición, la educación, etc., y este señalamiento obviamente es apreciado por la teoría crítica. Pero Horkheimer avanza y muestra que una posición que supone este tipo de escepticismo acaba diluyendo también -y paradójicamenteel potencial tanto de la razón como de la convicción o compromiso, y lo que es más, del pensamiento teórico. Porque para Montaigne no son dignos de confianza ni los sentidos ni los conceptos, por lo que "hipotecarse" a cualquier teoría es pura "ignorancia". En su opinión, la única sabiduría es no aferrarse a nada, puesto que nada es seguro. Y esto, como muestra Horkheimer, es problemático. En su forma únicamente descriptiva, puesto que se opone a cualquier prescripción, el escepticismo acaba adaptándose a lo real, dejando al mundo intacto, sin intervenir en él, sin tomar partido, sin "jugarse" por nada. De este modo, él se opone, en un mismo movimiento, a la teoría, a la política, a la moral, puesto que rechaza todo "constructivismo" en su respeto tácito a lo dado, a lo hegemónico (HORKHEIMER, 1995, p. 143-146).

${ }^{3}$ El artículo fue luego compilado en español en el libro Historia, metafísica y escepticismo (1995). 
El escepticismo, forma extrema del relativismo, al perder su función de crítica concreta, ético-política, deviene mero "objeto artístico", o "pensar ocioso", es decir, deviene adorno de la mente o juego de palabras, puro "entretenimiento" de quien evidentemente no tiene necesidad material ni simbólica de modificar nada en el mundo. Así, afirma Horkheimer, "la distinción entre verdad y mera diversión se difumina a nivel social". Es que el "espíritu" originariamente crítico de la burguesía moderna, luego de su triunfo sobre la aristocracia feudal, se apaga: pasa de comprometerse en lo público a reducirse a mero asunto privado; pasa de ser progresista a ser reacción contemplativa. Y así también es como la crítica pasa de ser una función ético-política del pensar, a convertirse en una rama especial del orden productivo: la de la cultura del ocio, del entretenimiento, del consumo pasivo e individual (p. 171-172). Por ello nuestro autor señala el estrecho vínculo entre la "evasión escéptica", la "tolerancia liberal", y el "menosprecio por el hombre". Sólo a partir de un relativismo extremo se logran esquivar las preocupaciones del hombre, hombre al que se acepta mientras se atenga a lo suyo, mientras no moleste ni altere la paz ajena. El valor principal que el escéptico niega es el de la "solidaridad" humana (p. 177) ${ }^{4}$. El escéptico, entonces, se guía por el principio del "dejarhacer", a menos que el hacer práctico del otro sea algún tipo de "actividad subversiva", o que su hacer teórico sea la "crítica de la totalidad", pues cualquiera de estas dos opciones conducirían al develamiento de sus propias condiciones de posibilidad. El escepticismo ataca a las "ideas ilusorias", o ideologías, pero sin atacar su "base estructural". Esto, para Horkheimer, es una "mala crítica, por no decir ninguna". Una crítica profunda, acabada, debe penetrar hasta las bases mismas de esas ideas ilusorias, pues de otro modo las deja indemnes en la práctica. Para lo cual es necesario que la crítica se realice desde el punto de vista de una determinada teoría de la sociedad en su conjunto: el mero "análisis de ideologías", sin una teoría más amplia que lo enmarque, no

\footnotetext{
${ }^{4}$ Como muestra Barahona Arriaza (1996, p. 180), la solidaridad, basada a su vez en el valor de la "compasión", es el fundamento de la postura ética horkheimeriana.
} 
modifica nada. Es que el objeto de la crítica no es la ideología sino el todo social -que incluye, obviamente, a las ideologías, pero no se reduce a ellas y además permite iluminar sus bases estructurales(p. 179-181).

El problema principal del escepticismo es que es crítico con todos menos consigo mismo: no alcanza a ver que su postura también puede devenir moda, también puede fundarse en un interés, también es altamente subjetiva. En este sentido, por su falta de autocrítica, el escepticismo también se hipostatiza y deviene "ídolo" (p. 183)5. Además, esta postura "desgaja" al pensamiento respecto de la práctica, dejando sin efecto concreto a su actividad intelectual, y conformándose con la "realidad perversa" (p. 187-188). Y aquí nuestro autor agrega una capa más de significado a su definición de teoría crítica. Si en los albores de la época moderna se daba un enfrentamiento entre la reforma y el escepticismo protestantes, como conflicto entre el "fanatismo", por un lado, y el "humanismo", por otro, estos elementos hoy se han desligado de esas "formas de vida" -específicamente religiosas y filosóficas- de modo tal que permiten ser integrados en una forma nueva ${ }^{6}$. La teoría crítica, entonces, pretende ser una "superación y conservación" de dicho antagonismo, una combinación de fanatismo y escepticismo que a la vez trasciende ambos momentos -al modo dialéctico hegeliano- y que conforma una tercera cosa, a la que el autor pone el nombre de "humanismo activo". Es humanista porque valora en alto grado al hombre, a sus necesidades, su sufrimiento, su bienestar. Es activo porque se compromete, critica, interviene públicamente y busca construir algo diferente a lo dado.

\footnotetext{
${ }^{5}$ Es interesante notar que, como muestra Jay (1974, p. 97), Horkheimer valoró en Friedrich Nietzsche (1998) su idea fundamental de que "toda gran verdad quiere ser criticada, no idolatrada". Sin embargo, observamos nosotros, el propio Nietszche parece haber caído presa de idolatría hacia su propio escepticismo, por lo cual suele tildarse a su filosofía de nihilista, es decir, de relativista o escepticista extrema.

${ }^{6}$ A esto llama Aguilera (2001, p. 15) la triple "constelación" horkheimeriana que articula filosofía, ciencia social y religión.
} 
El humanismo activo de la teoría crítica "toma partido", "no se lava las manos" (p. 195) .

Por ello no se trata sólo de rechazar sino también de construir. A este doble proceso lo había llamado G. W. F. Hegel (1989) "idea", concibiéndola como figura que se "activa" a partir de lo "negativo" en cada uno de sus momentos. Pero a diferencia de la dialéctica idealista hegeliana, la dialéctica materialista horkheimeriana "no está concluida", puesto que no acepta como dada la unidad entre historia y filosofía, la "armonía" entre ser y pensar, sino que dicha unidad es, a lo sumo, una pretensión, dado el carácter contradictorio y antagónico de la sociedad real. Por ello, el momento escéptico de la crítica debe dar paso a su momento activo, o también, el momento lógico de la crítica debe dar lugar a su momento histórico. Porque de otro modo el puro escepticismo deviene una nueva forma de la convicción, de la creencia, de la certeza, pero inconciente, no-criticada. Pero en la lucha activa e histórica de la crítica hay tan poca "certeza teórica" como "certeza práctica": hay tan poca garantía del éxito de dicha lucha como de estar comprometido con el valor correcto; y sin embargo, la teoría se compromete, pero conciente de su incertidumbre. Esta incertidumbre tiene que ver, por supuesto, con lo que podríamos llamar la apertura azarosa, contingente y a todas luces incognoscible a priori del despliegue histórico, que exige no sólo "agudeza de entendimiento" sino muchas veces, también, "poner la vida en juego" (HORKHEIMER, 1995, p. 197199). A diferencia del escepticismo, la teoría crítica no convierte en "absolutismo antiteórico" su constatación de la "transitoriedad del conocimiento", puesto que ella, combinada con la de la "maldad existente", da forma a un "tenaz interés en un futuro mejor" (p. 201).

\footnotetext{
${ }^{7}$ Esta es una prueba patente -a la que también suscribe del Valle (2010, p. 56)- del hecho de que el elemento teológico en Horkheimer no es un giro conservador de su vejez, sino que ya estaba presente desde sus escritos de juventud, y aunque la tendencia ciertamente se profundiza hacia el final de su vida, ella constituye claramente un elemento progresista, conectado a la idea de reforma e incluso a veces a la de revolución.
} 


\section{La función social de la filosofía (1940)}

En un artículo posterior titulado "La función social de la filosofía", escrito en 1940 para la misma Revista para la investigación social, Horkheimer establece una distinción entre la filosofía y el resto de las "actividades intelectuales", dado que, en su opinión, en estas últimas, aun cuando existan "controversias", se admite alguna "orientación general" común, de modo tal que los "representantes" de cada ciencia acuerdan respecto de su objeto y de su método, mientras que, en la filosofía, las escuelas rivales se refutan de tal manera que "niegan como radicalmente falsas" a toda teoría y a la totalidad de las mismas que no sea la suya propia (HORKHEIMER, 1974, p. 274) ${ }^{8}$. Esta postura del autor, que por cierto no vuelve a encontrarse en otros escritos, es altamente polémica. En primera instancia, podríamos señalar que lo mismo que el autor señala para la filosofía ocurre en todas las ciencias sociales y humanas. De hecho, la controversia radical es en realidad un rasgo inherente a cualquier actividad intelectual, incluso a las ciencias naturales (KUHN, 1971). Por ello es que nuestra hipótesis desde la cual leer este artículo de Horkheimer es la de que lo que él afirma acerca de la filosofía es también adecuado a las ciencias humanas y sociales en general y a la sociología en particular. Por ello, de aquí en más, cada vez que el autor diga filosofía, nosotros diremos filosofía y ciencias sociales: de este modo, por ejemplo, el título mismo del artículo debería ser, a nuestro entender, "la función social de la filosofía y las ciencias sociales"' . Aclarado esto, podemos comenzar.

\footnotetext{
${ }^{8}$ El artículo fue luego compilado, ya en su original versión en alemán, pero también en español, en el libro Teoría crítica (1974).

9 Para justificar esta hipótesis, nos basamos en el hecho de que el propio Horkheimer, en textos de la misma época, como "Materialismo y metafísica", de 1933 (Horkheimer, 1999), afirmaba que la distinción entre filosofía y ciencias sociales no era una distinción de principio, sino apenas un producto de cierta inevitable división del trabajo intelectual.
} 
Horkheimer afirma que la filosofía -y las ciencias socialespresentan un "carácter refractario", derivado de sus "principios inmanentes", respecto de la realidad. $Y$ es que, en tanto se caracterizan por ser reflexiones sobre el mundo humano, no pueden permitirse tomar a ninguno de sus elementos como "dados". Por ello, los filósofos y cientistas sociales consecuentes, serán aquellos para quienes "ni los conceptos científicos ni la forma de la vida social, ni el modo de pensar dominante ni las costumbres prevalecientes deben ser adoptados como hábito y practicados sin crítica" (HORKHEIMER, 1974, p. 276). En el fondo, es siempre respecto a esto que se plantean las discusiones en filosofía y en ciencias sociales, porque ellas carecen de un "campo de actividad fijamente delimitado dentro del ordenamiento existente". Aunque existen muchas clasificaciones y subdivisiones respecto a las porciones de realidad de las que cada una de ellas debería ocuparse, justamente, ellas son constantemente disputadas, de allí que sea poco clara su conexión directa -y con ello, su utilidad instrumental- con dicha realidad. Frente a esta incertidumbre y falta de claridad, no le queda a la filosofía ni a las ciencias sociales otra opción más que "confiar en su propia actividad teórica"10. $\mathrm{Y}$ esto en contra de aquellos sujetos que, en palabras del autor, se esfuerzan por "vender" la filosofía o las ciencias sociales, es decir, por demostrar su utilidad en la resolución de los problemas prácticos de la vida cotidiana. Pero si esto fuera cierto -y para el autor no lo es-, la filosofía y las ciencias sociales no serían más que "servidoras" del orden social establecido, en lugar de ser sus "críticas", que es la función que Horkheimer les asigna. Sucumbir a la idea de que la filosofía y las ciencias sociales "sirven" para algo, en un sentido instrumental, equivale a sucumbir a la idea de que en el fondo no existe tal cosa como la filosofía o la ciencia social como entidades con valor propio, con un papel propio. Equivale a

\footnotetext{
${ }^{10}$ Como muestra Alarcón Olguín (2002, p. 5), según Horkheimer la teoría crítica, en tanto "hipótesis en proceso de cambio" permanente, es susceptible de un "devenir dialéctico que puede reducir incertidumbres, pero dejando siempre puntos oscuros".
} 
sucumbir, en palabras del autor, a la idea de que "el pensamiento sistemático, en los momentos decisivos de la vida, debe retirarse a un segundo plano"; en una palabra, implica caer en el escepticismo y el nihilismo, y por ende en la falta de compromiso (p. 279-280).

La función de la filosofía y de la ciencia social es entonces la crítica de lo establecido, pero esto no implica la "actitud superficial" de objetar compulsivamente ideas o hechos aislados, lo cual haría del filósofo o del cientista social un "cómico personaje". Tampoco implica la suma de esta objeción compulsiva y de la "recomendación de remedios" para los males objetados -hemos visto que esto implicaría reducir a la filosofía y las ciencias sociales a su utilidad instrumental-. La meta de la crítica según la entiende Horkheimer es "impedir que los hombres se abandonen a aquellas ideas y formas de conducta que la sociedad en su organización actual les dicta", sin reflexión previa, sin haber puesto dicha idea o forma de conducta en perspectiva, sin haber analizado sus condicionamientos y sus consecuencias, y sin haber estudiado las alternativas (p. 282). Para el autor, incluso las teorías más abstractas, incluso las más metafísicas y trascendentales, se "basan" en problemas y categorías histórico-sociales sin las cuales no se pueden comprender. Por ello "un análisis exhaustivo del contenido de filosofemas puramente teóricos resulta una de las más interesantes tareas de una investigación moderna" filosóficocientífica. Esta tarea, sin embargo, no debe confundirse con la de una "sociología del conocimiento", que simplemente relaciona cada teoría o ideología con un grupo, sin ubicar a este último en la totalidad social y sin localizar sus mutuas interrelaciones ${ }^{11}$. Pero sí es central para el pensamiento crítico, puesto que la filosofía y las ciencias sociales son "el intento metódico y perseverante de introducir la razón en el mundo", mostrando sus contradicciones.

${ }^{11}$ Como señala Castro-Gómez (2008, p. 117), la noción de "totalidad" de la teoría crítica es muy similar a la noción poscolonial de "sistema-mundo": ambas pretenden abarcar a su objeto social como una unidad, a la vez que estudiar las interconexiones entre sus distintas partes, con especial atención a sus contradicciones y "consecuencias perversas". 
Esto último es lo que hace que su posición sea "precaria y cuestionable". La filosofía y la ciencia social, afirma Horkheimer en una fórmula que luego se hará famosa con Pierre Bourdieu (1990), “es incómoda, obstinada y, además, carece de utilidad inmediata; es, pues, una verdadera fuente de contrariedades" (HORKHEIMER, 1974, p. 285).

Horkheimer no descarta la posibilidad de que algún día sobrevengan épocas "en las que sea posible arreglárselas sin teorías"; pero esas épocas ciertamente no han sobrevenido aún, por lo que eludir la instancia teórica del trabajo filosófico y científico sólo puede conducir a un "empequeñecimiento" del hombre -un achicamiento de sus potencialidades-, que entonces queda "inerme frente a la violencia" del mundo (p. 286). Es cierto, concede el autor, que a veces la teoría puede "perderse en un idealismo hueco" -no atento a sus condicionamientos materiales-, o bien "caer en una retórica fatigante y vacía" -como hemos visto para el caso del escepticismo o del relativismo extremo-, pero estas no constituyen las "formas verdaderas" de la teoría. Y de hecho, afirma con ironía, si de "superficialidad" se trata, ella es mucho más frecuente en la "llamada investigación empírica" -cuando ella se mantiene en el nivel descriptivo y no profundiza en la explicación de condicionamientos o en el señalamiento de prescripciones a partir de compromisos-. Y emerge aquí la cuestión de la utopía: la utopía como metodología exclusiva no es la forma adecuada de resolver los problemas prácticos sociales, puesto que las contradicciones reales no pueden eliminarse mediante su eliminación en el plano del pensamiento. En este sentido, la utopía debe ser complementada con el análisis filosófico-científico de, por un lado, las relaciones sociales existentes, y, por otro, de las "tendencias" albergadas en su seno como posibilidades de desarrollos futuros alternativos. Si se permite el neologismo, se trata de "cientifizar" la utopía, de construirla en base a conocimientos sólidos y comprobados y no sólo a partir de deseos ${ }^{12}$. Evidentemente, de todos modos, esta

\footnotetext{
${ }^{12}$ A esto mismo lo denomina Gambarotta (2014, p. 87) "utopía-posible", lugar en el que se entrecruzan un elemento cognoscitivo y uno valorativo.
} 
mirada comparte con la mirada utópica clásica la "confianza en las posibilidades de la humanidad", "su optimismo respecto a las conquistas potenciales del hombre" (ídem).

La crítica, por ello, contiene el elemento negativo del rechazo, de la condena o de la "maledicencia" contra ciertos existentes, pero tiene también este elemento positivo. Esto no quiere decir que, del pensamiento del pasado, sólo puedan rescatarse aquellas obras o pensadores críticos, puesto que no debe igualarse teoría a política. Las teorías tienen múltiples y complejos aspectos, tal que pueden retomarse de ellas ciertos elementos y conjugarlos con otros tornándolos más críticos de lo que eran originariamente. -O al revés, obras o pensadores originariamente críticos pueden luego ser utilizados en un sentido reaccionario-. Como afirma brillantemente nuestro autor, "sólo en épocas excepcionales la filosofía misma se vuelve política", lo mismo que la ciencia. Esta idea nos parece un adelanto claro de lo que luego un autor como Jeffrey Alexander (1983) señalará como las distintas dimensiones de la realidad tal como es abordada por la ciencia, dimensiones que, aunque conformando un "continuum", resultan relativamente autónomas las unas respecto de las otras: así, por ejemplo, las posturas ideológicas respecto de los supuestos teóricos en sentido estricto, de un cierto cuerpo de pensamiento. Volviendo a Horkheimer, y para terminar, podemos citar sus propias palabras por su elocuencia respecto a lo que considera la función de la filosofía -y las ciencias sociales-, o más específicamente, la misión de la crítica: "nuestra misión actual es [...] asegurar que en el futuro no vuelva a perderse la capacidad para la teoría y para la acción que nace de ésta". Como puede verse, la acción emerge de la teoría, pero no se confunde con ella, que debe mantenerse como entidad con valor propio (HORKHEIMER, 1974, p. 287-289).

\section{Dialéctica de la ilustración (1944/1947)}

Ahora sí, podemos abocarnos al análisis de nuestro último texto seleccionado. En 1944 sale a la luz en mimeógrafo -y luego en 1947 en edición de imprenta- la obra que Horkheimer coescribe 
con su colega Theodor Adorno, Dialéctica de la ilustración. En el "Prólogo" los autores señalan que, a contrapelo de la tendencia hegemónica en ciencia, que es la de una "creciente decadencia de la cultura teórica", ellos buscan contribuir con este libro a la crítica de doctrinas. Esto, con el objetivo de evitar lo que siempre sucede al pensamiento cuando se vuelve "triunfante": abandona su elemento crítico y se convierte en "instrumento al servicio de lo existente", transformando así lo que tenía de positivo -y que paradójicamente es su elemento negador- en algo negativo -que paradójicamente suele ser leído como productivo- ${ }^{13}$. La "metamorfosis" de la crítica en afirmación de lo instituido tiene consecuencias específicas en el plano teórico del mundo social: su verdad -histórica, moral- se "volatiliza" en el momento mismo en que sus "portavoces oficiales" "liquidan" al conjunto de ideas que les permitió "conquistar un puesto bajo el sol". La teoría, cuando deja de ser crítica, se "prostituye", metáfora que entendemos en el sentido de que una doctrina se vende al mejor postor, sometiéndose a sus deseos como a las órdenes de un cliente, en una sociedad -capitalista, consumista- en la que "el cliente siempre tiene la razón". Por ello pueden sostener los autores que "la censura de la imaginación teórica abre camino a la locura política", porque si la teoría es imaginativa cuando trasciende lo real, y esa trascendencia es política, entonces la evitación de dicha trascendencia imaginativa implica subsumirse a la política real, que pierde su razón de ser política (HORKHEIMER Y ADORNO, 2001, p. 51-53). De un modo similar, en el "Prólogo a la reedición alemana" de 1969, aclaran que ya no "mantienen inalterable" todo lo que habían sostenido

\footnotetext{
${ }^{13}$ Como muestra Sisto (2002, p. 284), el nombre que adopta en este libro aquella dialéctica que no detiene su impulso crítico es el de "negación determinada", que los autores toman de Hegel (1985) pero modificándola. Así, para ellos, la negación determinada es la crítica de toda situación existente, en tanto ella pretende ser absoluta. Y como sostiene Abril (2009, p. 7-8), la negación determinada es aquella que, aunque busca poner en evidencia la falsedad de todo juicio absolutista, sin embargo no necesariamente abandona lo que cuestiona, pues ella no es relativista.
} 
en esas páginas veinte años antes, porque "eso no sería compatible con una teoría que atribuye a la verdad un momento temporal". Sin embargo, aclaran que deciden republicarlo en su contenido original puesto que veinte años después los mueve el mismo objetivo y el mismo método: el pensar crítico, que "no se detiene" ante la prosecución de la historia -aunque la tiene en cuenta-. Este pensar crítico "exige" tomar partido, precisamente, a favor de aquellos elementos progresivos, sobre todo cuando ellos más "impotentes" parecen frente a los acontecimientos del mundo. Es que la teoría crítica, aunque es crítica de la teoría, "no quiere renunciar" a ella (p. 49-50).

Ya en lo que hace al contenido del libro propiamente dicho, Horkheimer y Adorno muestran, en línea con los estudios anteriores del primero, cómo el "proceso sin fin de la ilustración", característico de la modernidad, lleva a que toda concepción teórica caiga inevitablemente bajo la "crítica demoledora de ser sólo una creencia", y en el extremo, mera "mitología"14. Como ya hemos visto, esto es el producto de la crítica cuando ella no se ve orientada por una convicción moral conciente, por un compromiso, sino que se despliega como mero formalismo escéptico y, en el fondo, nihilista. Mediante este escepticismo ilustrado, todo "lo distinto es igualado", puesto que se atacan con igual falta de escrúpulos las ideas progresistas y las reaccionarias, lo cual lleva a la postura nihilista de que, como todo da lo mismo, nada ha de hacerse ( $p$. 66-67). En nuestra opinión, es posible equiparar esta postura escéptica radical con lo que ya Karl Marx (1978) había tildado de "crítica crítica", es decir, como el mismo nombre lo dice, de crítica desmedida en tanto no se aferra a nada, en tanto cae en mera formalidad, y, paradójicamente, cayendo por ello en una nueva

${ }^{14}$ Como afirma Macedo Osorio (2013, p. 74), la ilustración no es tanto una época histórica concreta como una específica relación humana con el mundo. Y la lógica de la ilustración, al considerar todo objeto como idéntico a sí mismo, y sólo a sí mismo, rechaza la idea, subyacente a toda teoría, de que "una cosa puede ser lo que no es todavía", idea rechazada como "residuo mitológico" (Kolakowski, 1985, p. 361). 
forma de lo dogmático, de lo sagrado ${ }^{15}$. Frente a la crítica crítica, Marx por supuesto defiende a la crítica a secas, como en la crítica de la economía política. Volviendo a Horkheimer y Adorno, ellos sostienen que, desde posturas como las de quienes Marx llamaba "la sagrada familia", lo que "existe de hecho", así, "es justificado", y como además se quita legitimidad a la instancia teórica del conocimiento, éste "se limita a la repetición" de lo existente, con lo que "el pensamiento se reduce a mera tautología" (HORKHEIMER Y ADORNO, 2001, p. 80).

Frente a este vaciamiento de la teoría por parte de la crítica escéptica, quienes aún defienden la combinación de conocimiento y moral -incluso de una moral de izquierdas- caen en una postura positivista, por excesivamente empirista, como muestran algunos ejemplos clave de aquel entonces como las propuestas del llamado Círculo de Viena, que los autores encuentran sobre todo en la figura de Rudolf Carnap (NEURATH, CARNAP Y HAHN, 2002) ${ }^{16}$. $Y$ en consonancia con esa teoría positivista, la praxis también "queda a merced del mecanismo sin trabas de la historia universal" (HORKHEIMER Y ADORNO, 2001, p. 84, n. s/n). La teoría se reduce así a un instrumento altamente sofisticado, pero como explican nuestros autores, sólo un instrumento "universalmente disponible", es decir, accesible "para todos", puede llegar a ser crítico del "dominio a cuyo servicio creció". Sólo así la racionalidad

\footnotetext{
${ }^{15}$ Así, sostienen los autores, a pesar de la afirmación de la ilustración de haber dado por tierra por con la "mitopoiesis" de la era premoderna a partir del fortalecimiento de la racionalidad, ella misma acabó constituyendo un nuevo mito: el de su existencia como pura racionalidad e incluso el de su propio progreso (JAY, 1974, p. 420).

${ }^{16}$ Como muestran Araujo y Medina (2014), tanto la Escuela de Frankfurt como el Círculo de Viena construyen teorías que no reniegan de su orientación política. Pero como marca Sotelo (2010, p. 273), aunque la Escuela de Frankfurt y el Círculo de Viena comparten una crítica a la metafísica, ella no es del mismo tenor en cada caso: mientras que los positivistas lógicos rechazan de plano cualquier asunto metafísico en tanto carece de referentes empíricos, los frankfurtianos buscan trascender los datos positivos de la realidad a la vez que poner de relieve la función social de las ideas metafísicas.
} 
emerge como algo distinto al dominio (p. 90). Del mismo modo, una praxis que busque "subvertir" el dominio dado en un momento histórico determinado depende de la "intransigencia de la teoría", de su no ceder, de su no venderse -para volver a utilizar la metáfora del Prólogo-frente a la "inconciencia con la que la sociedad permite reificarse al pensamiento". Es decir, el vaciamiento de la teoría reifica el pensamiento, lo vuelve inmóvil y ahistórico de un modo inconciente, naturalizado, y sólo puede quebrarse esa cosificación extrema de la capacidad humana universal que es la razón a partir de volver a unir la teoría con la crítica, concientizando esa necesidad. Sólo una teoría de "espíritu" intransigente, no prostituido, puede intervenir en la historia, "reorientándola" de manera conciente en función de un compromiso (p. 94).

Más adelante, los autores añaden que "todo pensamiento que no tienda al sistema carece de dirección o es autoritario", es decir, que sólo las teorías que se preocupan abiertamente por su estructura y coherencia interna, así como por su profundidad conceptual y filosófica, pueden rebatir la tendencia al dominio, producto de la cosificación, que todo instrumento producido por el hombre parece tener, a pesar suyo, así como esa otra tendencia, opuesta a la primera, al escepticismo que se aloja en todo pensar ilustrado (p. 130). Dado el proceso de "formalización" creciente de la razón, producto del avance de la modernidad, la teoría misma se va convirtiendo cada vez más en algo "incomprensible", a la vez sofisticado y carente de sentido, puesto que cuanto más se especializa más se transforma en mera conjunción de "signos operacionales" vacíos. Es frente a este proceso histórico que se sitúa el llamado de los autores a la elaboración de teorías sistemáticas y críticas, en el sentido recién subrayado (p. 140). Porque de otro modo, en el marco histórico descrito, en el que la "industria cultural" es la nueva forma adoptada hegemónicamente por el plano simbólico de la vida del hombre, "desaparece tanto la crítica como el respeto", y el pensar se torna mera ejecución de juicios irreflexivos, dictados por las modas sucedidas tras las pantallas del mundo. El juicio crítico se vuelve juicio "mecánico", y el juicio respetuoso del hombre se torna apenas un "culto efímero" basado en la celebridad o la exclusión azarosa (p. 205; 244). 
En esta obra conjunta, los autores no sólo escriben en prosa académica; también redactan una serie de notas dispersas que abordan los mismos tópicos pero en otro género discursivo, y que aparecen hacia el final del libro. En esa sección, llamada "Apuntes y esbozos", Horkheimer y Adorno realizan una serie de sugerencias importantes para nuestras preocupaciones. En la nota titulada "Transformación de la idea en dominio", por ejemplo, realizan una distinción entre "sistemas teóricos" aceptados y "marginados"; no casualmente, muestran, los sistemas teóricos que acaban marginados por la historia resultan siempre, al analizarlos, menos "rígidos y centralizados" que los aceptados: en ellos siempre se halla "un cierto toque de anarquía", pues en ellos la "idea" -como momento constructivo, distinto de lo dado, y por ello transformadora- "cuenta más" que la "administración" -es decir, que la reproducción ordenada de lo estatuido- (p. 255) ${ }^{17}$. En "Para Voltaire", añaden que "el objeto de la teoría no es lo bueno, sino lo malo"; evidentemente, están pensando en una teoría de tipo crítico, con su elemento negativo sobre el que ya hemos hablado. Para que la teoría pueda ser el vehículo de la libertad, de lo positivo, su "tema", su objeto de estudio, debe ser la "opresión", lo negativo (p. 261). Del mismo modo, en "Para una crítica de la filosofía de la historia", muestran que el pensamiento mismo es siempre un elemento negativo, puesto que su "correlato" es la historia, entendida como objeto "construible" desde una teoría, y puesto que la historia es "horror". En este marco, la "esperanza de un estado mejor", concebida como algo distinto a la "pura ilusión", no puede fundarse en la mera "aseveración" de su garantía, estabilidad y definitividad -es decir, en su aserción dogmática- sino por el contrario en la "falta de respeto" por todo lo "sólidamente fundamentado" en medio del "sufrimiento universal". En otras

\footnotetext{
17 Respecto del dilema entre la reproducción de lo dado o la producción de algo diferente, Gambarotta (2014, p. 74-76) habla de la generación de una "discontinuidad" en lo continuo, de una "abertura" en un "cosmos" cerrado, de modo tal de resquebrajar lo "posible-pensable" a partir de lo "imposibleimpensable".
} 
palabras, sólo cuestionando lo dado, que es, a todas luces, terrible, puede comenzar a ser más que una utopía la idea comprometida de una historia progresista (p. 268). En la nota "El pensamiento", Horkheimer y Adorno prosiguen en la crítica de quienes conciben a toda teoría como una receta para la acción, como un dogma, ya sea éste positivo o negativo, o sea, podríamos decir, imperativo o prohibitivo. Quienes así piensan, "toman toda afirmación en el sentido de una profesión de fe definitiva, o de una orden o de un tabú", es decir, "quieren someterse a la idea como a un dios, o bien la atacan como a un ídolo"18. En este sentido, los dogmáticos "no tienen libertad" frente a la teoría, elemento indispensable si se pretende que esa teoría se efectivice en la historia, para lo cual es necesario tratarla con cierta soltura (p. 290). Lo que queda claro aquí, entonces, es que compromiso tampoco es igual a dogmatismo.

\section{Conclusiones}

Luego del análisis detallado de este que hemos denominado período intermedio de la obra de Max Horkheimer, y de los tres textos que en él están contenidos, podes trazar unas ideas a modo de conclusión parcial.

En primer lugar, es notable que la noción de compromiso de Horkheimer se sitúa en una cadena de herencias intelectuales cuyo origen podemos localizar en Marx. Así, la idea de una teoría crítica comprometida -es decir, ni escéptica, ni relativista, ni nihilista, pero tampoco dogmática-, presenta resonancias del cuestionamiento marxiano a la crítica-crítica sacralizante, y de su defensa, por el

\footnotetext{
${ }^{18}$ En este sentido, es claro que, como muestra del Valle (2010, p. 61), Horkheimer es laico a pesar de sus referencias teológicas: él no afirma -aunque tampoco niega- la existencia de alguna entidad trascendente, pues tanto la certeza de su existencia como de su no existencia implicaría una postura dogmática. Nuestro autor cabe ser clasificado, por esto, como un agnóstico. O como afirma Alarcón Olguín (2002, p. 1), su obra pasa de una "crítica agnóstica” a una "crítica mística", pero no confesional. Acerca de la relación entre la teoría crítica horkheimeriana y la teología, FRAGA, 2017.
} 
contrario, de la crítica filosófico-científica a secas. Asimismo -y aunque queda para un estudio posterior el desarrollar a fondo esta idea-, encontramos en la postura horkheimeriana de una teoría crítica oposicionista, un antecedente del planteo bourdiano en torno a una ciencia social incómoda y molesta con respecto a lo estatuido.

En segundo lugar, quisiéramos hacer notar cómo la noción de compromiso delineada por Horkheimer supone un entrecruzamiento -aunque no una igualación absoluta- entre teoría y práctica, entre pensamiento y acción, entre academia y política, $\mathrm{y}$, aún más relevante, entre ciencia y moral, entre conocimiento y convicción, o para decirlo con el vocabulario típico de la sociología, entre juicios de hecho y juicios de valor. Nuestra disciplina no es menos sino más legítima al comprometerse, porque su legitimidad se la da la historia.

En efecto, podríamos sistematizar las conceptualizaciones del autor en torno a la problemática del compromiso, según ella es desplegada en los tres textos clave analizados, diciendo que, para Horkheimer, el compromiso presenta once dimensiones. En primer lugar, el compromiso implica una "toma de posición" o "toma de partido". En segundo lugar, el compromiso se ubica en el punto de cruce entre la "razón" y la "fe", entre la "argumentación" y la "convicción", entre "escepticismo" y "fanatismo", o entre la "duda" y la "certeza". En tercer lugar, el compromiso implica enmarcarse explícitamente en un "espacio teórico" determinado, el cual sin embargo no es "aplicado dogmáticamente", sino de manera "reflexiva" y "mediada". En cuarto lugar, el compromiso supone la participación "activa" en la "cosa pública". En quinto lugar, el compromiso presupone la posibilidad y la deseabilidad de la "crítica", especialmente desde una perspectiva "humanista". En sexto lugar, el compromiso asume la falta de "garantías" acerca del triunfo de sus ideas, y acepta la posibilidad del éxito tanto como del fracaso, a pesar de los cuales permenece comprometido. En séptimo lugar, el compromiso no es nunca "utilitario" o "instrumental", sino que su función apunta más allá de esos valores dominantes, hacia las "cuestiones decisivas" de la vida humana. 
En octavo lugar, el compromiso, referido a la tarea específicamente intelectual o académica, implica trascender tanto el plano meramente "descriptivo" de hechos como el plano "explicativo" de procesos, hacia el plano "prescriptivo" de transformaciones. En noveno lugar, el compromiso no es "formal", sino "contenidista", pues se colma de valores concretos a defender y por los cuales luchar. En décimo lugar, el compromiso es "intransigente", no se "prostituye" ni se "vende", sino que se mantiene firme. Y en undécimo lugar, el compromiso se mueve por "utopías", pero no se reduce a ellas, puesto que no sólo imagina sino que además analiza filosófica y científicamente las realidades concretas con sus tendencias reales.

A modo de síntesis, y siguiendo el guiño metafórico utilizado por el propio Horkheimer, podríamos afirmar que, si la teoría crítica es aquella que "no se lava las manos", entonces, del mismo modo, comprometerse significa "meter las manos en la masa", o bien, "poner manos a la obra". Y en una suerte de análisis etimológico -sólo válido para el vocablo en español-, podríamos afirmar que "com-prometerse" significa "prometerse-con" algo, que en el caso de nuestro autor suele llevar por nombre "justicia social".

\section{Referências}

ABRIL, F. Para una relectura de la crítica a la razón de Theodor W. Adorno y Max Horkheimer. Tópicos, n. 17, p. 1-20, 2009.

AGUILERA, A. Pesimismo en la teoría, optimismo en la praxis. En: HORKHEIMER, M. Autoridad y familia y otros escritos. Barcelona: Paidós, 2001.

ALARCÓN OLGUÍN, V. Max Horkheimer: los reductos de la crítica. Casa del Tiempo, p. 1-7, 2002.

ALEXANDER, J. C. Theoretical logic in sociology I. Positivism, presuppositions, and current controversies. Londres: Routledge, 1983. 
ARAUJO, C. I. y MEDINA, C. G. Acerca de la polémica NeurathHorkheimer: ciencia y política. Diánoia, v. 59, n. 72, p. 113-129, 2014.

FRAGA, E. Dialógica, polémica, retórica, tópica y deíctica. Las dimensiones argumentativas de la crítica. Revista Horizontes Filosóficos, n. 5, p. 39-60, 2015.

FRAGA, E. Elementos teológicos en la teoría crítica de Max Horkheimer. Un análisis de textos claves. Revista Itinerantes, n. 7, p. 191-212, 2017.

BARAHONA ARRIAZA, E. Razón, verdad y crítica: momentos epistemológicos en la Dialéctica de la ilustración de M. Horkheimer y T. Adorno. Anales del Seminario de Metafísica, n. 30, p. 167184, 1996.

BOURDIEU, P. Sociología y cultura. México: Grijalbo, 1990.

CASTRO-GÓMEZ, S. Teoría tradicional y teoría crítica de la cultura. Impulsos, n. 29, p. 113-124, 2008.

DEL VALLE, N. Justicia, teología y teoría crítica en la obra tardía de Max Horkheimer. Reflexiones sobre política radical. Alpha, n. 31, p. 55-67, 2010.

GAMBAROTTA, E. Hacia una teoría crítica reflexiva. Max Horkheimer, Theodor W. Adorno y Pierre Bourdieu. Buenos Aires: Prometeo, 2014.

HEGEL, G. W. F. Fenomenología del espíritu. Madrid: Fondo de Cultura Económica, 1985.

HEGEL, G. W. F. Introducción a la historia de la filosofía. Madrid: Aguilar, 1989.

HORKHEIMER, M. Teoría crítica. Buenos Aires, Amorrortu, 1974. HORKHEIMER, M. Historia, metafísica y escepticismo. Barcelona: Altaya, 1995.

HORKHEIMER, M. Materialismo, metafísica y moral. Madrid: Tecnos, 1999. 
HORKHEIMER, M. y Adorno, T. Dialéctica de la ilustración. Fragmentos filosóficos. Madrid: Trotta, 2001.

JAY, M. La imaginación dialéctica. Una historia de la Escuela de Frankfurt. Madrid: Taurus, 1974.

KOLAKOWSKI, L. La escuela de Frankfurt y la 'teoría crítica'. En: Las principales corrientes del marxismo III. La crisis. Madrid: Alianza, 1985.

KUHN, T. La estructura de las revoluciones científicas. México: Fondo de Cultura Económica, 1971.

MACEDOOSORIO, G. Teoría crítica en Max Horkheimer y Theodor Adorno. En: El carácter de dominio de la razón instrumental en la ciencia. A partir de Max Weber y Max Horkheimer. México: Universidad Autónoma Metropolitana, 2013.

MARX, K. La sagrada familia. Barcelona: Crítica, 1978.

MONTAIGNE, M. Ensayos I. Madrid: Gredos, 2005.

NEURATH, O., CARNAP, R. y HAHN, H. La concepción científica del mundo: el Círculo de Viena. Redes, n. 18, p. 103-149, 2002.

NIETZSCHE, F. La visión dionisíaca del mundo. En: El nacimiento de la tragedia. Madrid: Alianza, 1984.

NIETZSCHE, F. El ocaso de los ídolos, o cómo se filosofa a martillazos. Barcelona: Tusquets, 1998.

SISTO, H. M. La clave del iluminismo para Horkheimer y Adorno. Revista de Filosofía y Teoría Política, n. 34, p. 283-293, 2002.

SOTELO, L. Horkheimer y el primer proyecto de 'investigación social' de la Escuela de Frankfurt. Estudios, p. 269-277, 2010.

WIGGERSHAUS, R. La Escuela de Fráncfort. México: Fondo de Cultura Económica, 2010. 
